\title{
Soya protein attenuates abnormalities of the renin-angiotensin system in adipose tissue from obese rats
}

\author{
María E. Frigolet, Nimbe Torres and Armando R. Tovar* \\ Departamento de Fisiología de la Nutrición, Instituto Nacional de Ciencias Médicas y Nutrición Salvador Zubirán, Vasco de \\ Quiroga No. 15, Colonia Seccion XVI, Mexico DF 14000, Mexico
}

(Received 17 December 2010 - Revised 17 March 2011 - Accepted 25 March 2011 - First published online 22 June 2011)

\begin{abstract}
Several metabolic disturbances during obesity are associated with adipose tissue-altered functions. Adipocytes contain the reninangiotensin system (RAS), which regulates signalling pathways that control angiogenesis via Akt in an autocrine fashion. Soya protein (Soy) consumption modifies the gene expression pattern in adipose tissue, resulting in an improved adipocyte function. Therefore, the aim of the present work is to study whether dietary Soy regulates the expression of RAS and angiogenesis-related genes and its association with the phosphorylated state of Akt in the adipose tissue of obese rats. Animals were fed a $30 \%$ Soy or casein (Cas) diet containing 5 or $25 \%$ fat for $160 \mathrm{~d}$. mRNA abundance was studied in the adipose tissue, and Akt phosphorylation and hormone release were measured in the primary adipocyte culture. The present results show that Soy treatment in comparison with Cas consumption induces lower angiotensin release and increased insulin-stimulated Akt activation in adipocytes. Furthermore, Soy consumption varies the expression of RAS and angiogenesis-related genes, which maintain cell size and vascularity in the adipose tissue of rats fed a high-fat diet. Thus, adipocyte hypertrophy and impaired angiogenesis, which are frequently observed in dysfunctional adipose tissue, were avoided by consuming dietary Soy. Taken together, these findings suggest that Soy can be used as a dietary strategy to preserve adipocyte functionality and to prevent obesity abnormalities.
\end{abstract}

Key words: Soya: Renin-angiotensin: Adipose tissue: Vascularisation: Akt

Adipose tissue is now considered to be an endocrine organ in addition to playing its classical role in storing energy. The endocrine action of adipocytes involves secreting hormones or cytokines that are referred to as 'adipokines,(1). These molecules are mainly involved in energy equilibrium, lipid and glucose homeostasis, angiogenesis, adipogenesis and inflammatory response, among others. During obesity, the endocrine and metabolic functions of adipocytes are impaired $^{(2)}$. Therefore, adipocyte dysfunction has been related to systemic abnormalities associated with the development of the metabolic syndrome ${ }^{(3,4)}$.

Previous efforts have focused on the identification of molecular links between adipocyte function and hypertension in obesity. Particularly, human and rodent adipocytes express all of the components of the renin-angiotensin system (RAS) ${ }^{(5,6)}$. This means that fat cells produce the RAS precursor angiotensinogen (Agt), although the liver is generally the main source of this molecule. Agt is converted into angiotensin I due to the action of renin, and angiotensin I is converted into angiotensin II by an angiotensin-converting enzyme (ACE). Adipocytes express enzymes that synthesise angiotensin II from Agt and also express the angiotensin II receptors (ATR1 and ATR2) ${ }^{(7)}$. This suggests that adipocytes produce the effector hormone and are also able to sense it. Typically, angiotensin II exerts its effects in smooth vascular cells through the promotion of vasoconstriction by ATR1. In addition, angiotensin II induces aldosterone production and $\mathrm{Ca}$ flux in the heart ${ }^{(8,9)}$. Interestingly, during obesity, the mRNA abundance of Agt in the adipose tissue and circulating concentrations are increased ${ }^{(10-12)}$. In fact, adipose Agt can significantly contribute to the total concentration of Agt in obese subjects. Furthermore, ACE gene expression in adipose tissue has been correlated with $\mathrm{BMI}^{(13)}$. This evidence indicates that angiotensin produced by adipose tissue exerts systemic physiological effects but also modifies local adipocyte function.

In fact, the effects of angiotensin II on glucose metabolism have been recently studied in different cells. The infusion of angiotensin II into the abdominal subcutaneous adipose tissue reduces glucose uptake ${ }^{(14)}$. In smooth muscle vascular

Abbreviations: ACE, angiotensin-converting enzyme; Agt, angiotensinogen; ATR, angiotensin II receptor; Cas, casein; Cas HF, casein high-fat; DMEM, Dulbecco's modified Eagle's medium; HF, high fat; HPRT, hypoxanthine phosphoribosyltransferase; MMP, matrix metalloproteinase; RAS, reninangiotensin system; Soy, soya protein; Soy HF, soya protein high-fat; TIMP, tissue inhibitor of matrix metalloproteinase; VEGF, vascular endothelial growth factor.

*Corresponding author: Dr A. R. Tovar, fax +52 55 56553038, email tovar.ar@gmail.com 
cells, angiotensin II decreases insulin receptor substrate-1 phosphorylation and consequent glucose uptake ${ }^{(15)}$. This evidence suggests that insulin action can be impaired by angiotensin II in the adipose tissue. Insulin regulates adipogenesis through Akt activation, which has been described as an essential process during adipocyte differentiation ${ }^{(16-18)}$ and angiogenesis ${ }^{(19)}$. Thus, insulin signalling in adipocytes results in the formation of mature adipocytes and blood vessels as well as glucose internalisation.

Dietary factors are known to affect the functionality of adipocytes and may influence the regulation of RAS. We have demonstrated that the type of dietary protein can change the expression of several genes in the adipose tissue of obese rats in comparison with rats fed casein (Cas). Particularly, soya protein (Soy) consumption positively modifies the adipose tissue's transcriptome and metabolism, which in turn could ameliorate the metabolic syndrome ${ }^{(20)}$. However, there is no evidence whether the consumption of Soy regulates the gene expression of RAS and angiogenesis in adipose tissue. For these reasons, the aim of the present study is to determine the effect of Soy consumption on rat adipose tissue gene expression of RAS and angiogenesis components, vascularisation and angiotensin II-mediated Akt phosphorylation in a model of diet-induced obesity.

\section{Materials and methods}

\section{Animals and protocol}

Male Sprague-Dawley rats ( 4 weeks old) weighing an average of $100 \mathrm{~g}$ were obtained from Harlan Teklad (Mexico City, Mexico). All the rats were housed in individual cages in a controlled temperature environment with a $12 \mathrm{~h}$ light $-12 \mathrm{~h}$ dark cycle and had free access to water and food. The rats were fed four different diets for $160 \mathrm{~d}$. The diets were prepared from basic ingredients as described in Table 1. High-fat diets consisted of $25 \%$ fat. Cas high-fat (Cas HF) and Soy high-fat (Soy HF) contained $20.9 \mathrm{~kJ} / \mathrm{g}$, and control diets (5\% fat; Cas and Soy) contained $16.7 \mathrm{~kJ} / \mathrm{g}$. The diets had $30 \%$ of either Soy or Cas, and the dietary protein concentration was adjusted on the basis of protein purity (Cas 90.6\% and Soy $86 \%$ ). The animals fasted for $12 \mathrm{~h}$ and were killed with CO and a guillotine. The serum was stored at $-20^{\circ} \mathrm{C}$ for measuring the biochemical parameters, and the retroperitoneal adipose tissue was stored at $-70^{\circ} \mathrm{C}$ for the extraction of RNA. The protocol for the present study was approved by the Animal Ethics Committee of the Instituto Nacional de Ciencias Médicas y Nutrición Salvador Zubirán.

\section{Biochemical parameters}

The fasting serum cholesterol and TAG concentrations were measured by colorimetric kits (DiaSys Diagnostic Systems, Holzheim, Germany). Fasting serum glucose was measured using an YSI2700 select Biochemistry Analyzer (YSI Incorporated, Yellow Spring, OH, USA). Also, fasting serum leptin and insulin were measured using a Lincoplex kit (Linco Research, St Charles, MO, USA). Culture media angiotensin I
Table 1. Composition of experimental diets

\begin{tabular}{lcccc}
\hline Ingredients (\%) & Cas & Soy & Cas HF & Soy HF \\
\hline Cas* or Soy† & $33 \cdot 11$ & $34 \cdot 09$ & $33 \cdot 11$ & 34.09 \\
Dextrose & $27 \cdot 86$ & $27 \cdot 37$ & $17 \cdot 86$ & 17.37 \\
Maize starch & $27 \cdot 86$ & $27 \cdot 37$ & $17 \cdot 86$ & 17.37 \\
Maize oil & 5 & 5 & 5 & 5 \\
Lard & 0 & 0 & 20 & 20 \\
Mineral mix $\ddagger$ & 5 & 5 & 5 & 5 \\
Vitamin mix§ & 1 & 1 & 1 & 1 \\
\hline
\end{tabular}

Cas, casein; Soy, soya protein; Cas HF, Cas high-fat; Soy HF, Soy high-fat.

* 'Vitamin-free' Cas (Harlan Teklad Research Diets, Madison, WI, USA) † Supro 710 (Solae, México City, Mexico).

‡ Rogers-Harper (Harlan Teklad Research Diets).

$\S$ AIN-93-VX, Harlan Teklad Research Diets (mg/kg diet): nicotinic acid, 150; calcium pantothenate, 80; pyridoxine- $\mathrm{HCl}, 35$; thiamine- $\mathrm{HCl}$, 30; riboflavin, 30; folic acid, 10; D-biotin, 1; vitamin $\mathrm{B}_{12}, 0.1$; DL- $\alpha$ tocopheryl acetate $(500 \mathrm{IU} / \mathrm{g} ; 500 \mathrm{mg} / \mathrm{g}) 750$; vitamin A palmitate $\left(500000 \mathrm{IU} / \mathrm{g} ; 150 \mathrm{mg} / \mathrm{g}\right.$ ), 40; vitamin $\mathrm{D}_{3}$ (cholecalciferol, $500000 \mathrm{IU} / \mathrm{g}$; $1.25 \mathrm{mg} / \mathrm{g}$ ), 10 ; vitamin $\mathrm{K}$ (phylloquinone), 3.75.

and angiotensin II concentrations were assayed by RIA kits (Phoenix Pharmaceuticals, Inc., Burlingame, CA, USA).

\section{Real-time quantitative $P C R$}

Total RNA was extracted from retroperitoneal fat tissues by Chomczynski's method using guanidine thiocyanate ${ }^{(21)}$. For integrity analysis, $15 \mu \mathrm{g}$ of total RNA was separated by $1.0 \%$ agarose $/ 2 \cdot 2 \mathrm{M}$-formaldehyde gel electrophoresis. Of the total RNA from each animal, 300 ng were subjected to RT before PCR amplification with the Two-Step Master Mix (Applied Biosystems, Foster City, CA, USA). Parallel non-template control reactions were run in the absence of RNA to detect nucleic acid contamination in the reaction mixtures. TaqMan fluorogenic probes and oligonucleotide primers were designed by Applied Biosystems. TaqMan PCR assays for each target gene were carried out in triplicate in ninetysix-well optical plates with an ABI Prism 7000 Sequence Detection System (Perkin-Elmer Applied Biosystems). For every PCR sample, an amplification plot was generated from the collected data, and a threshold cycle $\left(C_{\mathrm{T}}\right)$ value was calculated with the software suite. Using the standard curve, $C_{\mathrm{T}}$ values for each gene were used to calculate the relative initial quantity of complementary DNA. Hypoxanthine phosphoribosyltransferase (HPRT) was used as an invariant control. Taqman assays for Agt (Rn00593114), ACE (Rn01416296), ATR1 (Rn01435427), ATR2 (Rn00560677), vascular endothelial growth factor a (VEGFa; Rn01511601), angiopoietin 2 (Rn01756774), matrix metalloproteinase 2 (MMP2; Rn01538170), a tissue inhibitor of matrix metalloproteinase-3 (TIMP3; Rn00441826_m1) and HPRT (Rn01527840) were obtained from Applied Biosystems.

\section{Adipocyte culture}

Adipocytes were obtained from retroperitoneal fat pads. The fat depots were resected under aseptic conditions, and adipocytes were isolated by collagenase digestion according to the procedure of Rodbell ${ }^{(22)}$ with minor modifications as described below. The fat pads were minced in the 
Krebs-Ringer HEPES buffer ( $\mathrm{pH} 7 \cdot 4$ ) containing 5 mM-D-glucose, $2 \%$ bovine serum albumin, $135 \mathrm{~mm}-\mathrm{NaCl}, 2 \cdot 2 \mathrm{~mm}^{-\mathrm{CaCl}_{2}} \cdot 2 \mathrm{H}_{2} \mathrm{O}$,

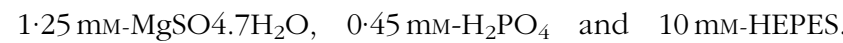
Adipose tissue fragments were digested in the Krebs-Ringer HEPES buffer with $1.25 \mathrm{mg} / \mathrm{ml}$ type II collagenase at $37^{\circ} \mathrm{C}$ with gentle shaking for $45 \mathrm{~min}$ at eighty cycles/min. The resultant cell suspension was diluted in $13 \mathrm{ml}$ of a cold KrebsRinger HEPES buffer. For washing, the cells were resuspended in $50 \mathrm{ml}$ of buffer and centrifuged at $400 \mathrm{~g}$ for $5 \mathrm{~min}$. The final wash was made with $13 \mathrm{ml}$ of the culture medium (Dulbecco's modified Eagle's medium (DMEM) containing 10\% fetal bovine serum). Floating cells were collected as primary adipocytes, plated on $6 \mathrm{~cm}$ dishes, and cultured at $37^{\circ} \mathrm{C}$ in $5 \% \mathrm{CO}_{2}$. Viability was calculated using trypan blue, and it always resulted in $90 \%$ or above. Each replicate of $10^{5}$ adipocytes was incubated with $2 \mathrm{ml}$ of DMEM containing $10 \%$ fetal bovine serum, and a $1 \%$ penicillin-streptomycin mixture. The cells were stimulated with insulin $\left(10^{-7} \mathrm{M}\right.$; Insuman, Aventis, Mexico) for $15 \mathrm{~min}$, or they were stimulated with insulin followed by angiotensin II (100 nm; Sigma-Aldrich, St Louis, MO, USA) for $30 \mathrm{~min}$. The unstimulated cell culture was used to collect the media and measure angiotensin concentration.

\section{Immunoblot}

After stimulation, the cells were lysed with cell lysis buffer (1\% Triton, 6.4 mm-NaCl, 1 mm-EDTA, 100 mm-NaF, 1 mm-sodium orthovanadate) and one tablet $/ 10 \mathrm{ml}$ of protease inhibitor mixture (Complete Mini; Roche Diagnostics, Werk Penzberg, Germany) and homogenised at $4^{\circ} \mathrm{C}$. The homogenate was centrifuged at $4000 \mathrm{~g}$ for $5 \mathrm{~min}$ before protein determination by the Lowry's method ${ }^{(23)}$. Equal amounts of protein $(100 \mu \mathrm{g})$ were mixed with a loading buffer, boiled for $5 \mathrm{~min}$, and separated by SDS-PAGE. After electrophoresis, the proteins were transferred to polyvinylidene difluoride membranes (Amersham Biosciences, Chalfont St Giles, Bucks, UK) using an electrophoretic transfer system (Bio-Rad, Hercules, CA, USA). The membranes were then treated with a blocking reagent (Bio-Rad) and incubated overnight at $4{ }^{\circ} \mathrm{C}$ with specific primary rabbit antibodies: anti-Akt or anti-phospho (Ser 473) Akt (sc8312, and sc7985R; Santa Cruz Biotechnology, Santa Cruz, CA, USA); primary antibody dilutions were 1:250 and 1:500, respectively. After washing, the membranes were incubated with horseradish peroxidase-conjugated secondary antibody (1:5000; Santa Cruz Biotechnology) for $1 \mathrm{~h}$ at room temperature. Finally, the blots were developed with enhanced chemiluminescence detection reagents (Millipore, Bedford, MA, USA). For quantitative analyses, a densitometric analysis of bands on immunoblots was done with the Sigma Scan software (Aspire Software International, Ashburn, VA, USA).

\section{Histological analysis}

Paraffin sections ( $4 \mu \mathrm{m}$ of thickness) of formalin-fixed fat pads were stained with haematoxylin and eosin and analysed with a Leica microscope equipped with a digital camera. For each sample, ten cells or five blood vessels in three areas were evaluated. Also, vessels in each area were identified and counted. Adipocytes and blood vessel areas with blood vessels were obtained using Leica software for digital imaging processing.

\section{Statistical analysis}

The results obtained in the present study are presented as the means with their standard errors, and they were evaluated with one-way or two-way ANOVA followed by Fisher's protected least significant difference test to determine statistical differences. The correlations between media levels of angiotensin and mean adipocyte area were assessed by the Pearson correlation test. Differences were considered statistically significant at $P<0.05$ and were indicated by the letters in the figures, where ' $a$ ' was the highest value $(a>b>c>d)$.

\section{Results}

\section{Weight gain, energy intake and biochemical parameters}

At the end of the study, rats fed a Cas HF or Soy HF diet gained significantly more weight than the respective control groups; however, those fed Cas gained more weight than those fed Soy (Fig. 1(A)). These results are in agreement with a previous study from our laboratory demonstrating that Soy induces less weight gain and less total body fat ${ }^{(24)}$. Differences in weight gain were not attributed to changes in energy intake because the amount of energy consumed, on average, for each group was not significantly different (Fig. 1(B)). The serum angiotensin I and II concentrations showed no statistical difference between groups (data not shown). However, adipocytes from rats fed Soy HF released lower angiotensin I (Fig. 1(C)) and angiotensin II (Fig. 1(D)) into the media culture than did rats fed Cas HF. The control groups did not show a significant difference with regard to angiotensin I or II release; however, the Cas group did have an increased media concentration when compared with the Soy group. Leptin and insulin serum concentrations were decreased by Soy consumption and by lower dietary fat content. On the other hand, serum glucose and cholesterol levels were increased in the Cas and Soy groups that were fed HF diets. The soya control group had a lower TAG serum concentration than the Cas control group (Table 2). Thus, Soy consumption resulted in a decrease in angiotensin release in cultured adipocytes and also reduced leptin, insulin and TAG serum concentration in rats.

\section{Angiotensin and angiogenesis-related gene expression in adipose tissue}

Unexpectedly, Agt mRNA abundance was the lowest in the adipose tissue of rats fed Cas HF. No differences were observed between the remainder of the groups. However, ACE expression was three-fold higher in the adipose tissue of rats fed HF compared with the control groups; this suggests enhanced angiotensin II production during obesity. The expression of ATR1 was lower in the Soy group compared 
(A)

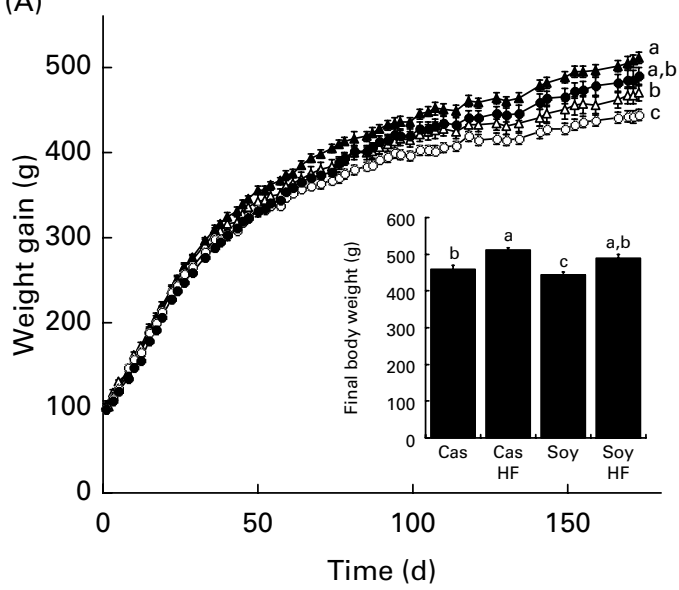

(C)

\begin{tabular}{|c|c|c|}
\multicolumn{1}{c}{ Protein } & Fat & Protein $\times$ fat \\
\hline 0.024 & NS & NS \\
\hline
\end{tabular}

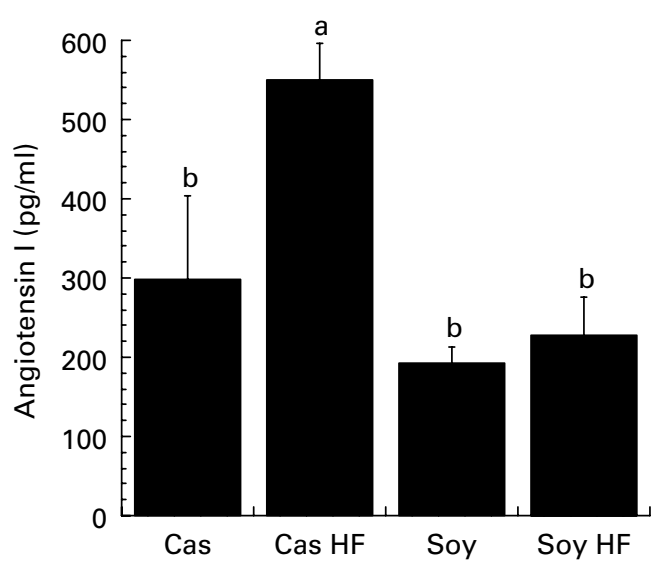

(B) 500

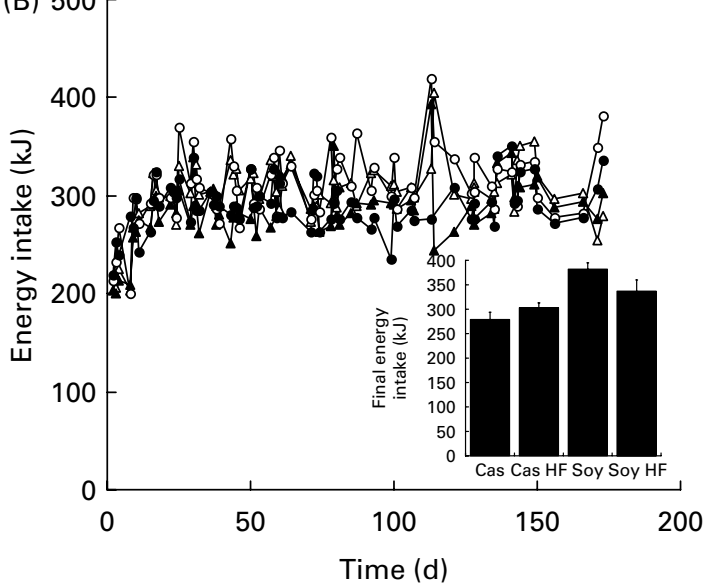

(D)

\begin{tabular}{|c|c|c|}
\multicolumn{1}{|c}{ Protein } & Fat & \multicolumn{1}{c}{ Protein $\times$ fat } \\
\hline 0.005 & NS & NS \\
\hline
\end{tabular}

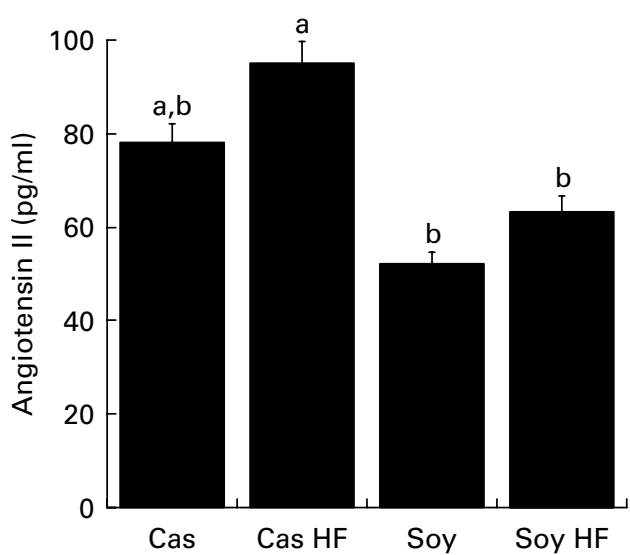

Fig. 1. Body weight gain and angiotensin media concentration are reduced by dietary soya protein (Soy) without changes in energy consumption. (A) Body weight gain, (B) energy intake, (C) angiotensin I media concentration, (D) angiotensin II media concentration from rats fed casein (Cas, $-\Delta-$ ), Cas high-fat (Cas HF, $-\mathbf{\Delta -}$ ), Soy $\left(-\mathrm{O}_{-}\right)$and Soy high-fat (Soy HF, $\left.-\bullet-\right)$ for $160 \mathrm{~d}$. Values are means, with their standard errors represented by vertical bars, $n 15 .{ }^{\mathrm{a}, \mathrm{b}, \mathrm{c}}$ Mean values with unlike letters were significantly different $(P<0.05)$.

with the Cas group, but the HF groups showed the opposite pattern. This means that Soy consumption accompanied by an adequate dietary fat concentration possibly attenuates ATR1-mediated functions. On the other hand, ATR2 mRNA abundance was not modified by the experimental diets. The critical angiogenic factors, VEGFa and angiopoietin 2 mRNA expression, were increased in the adipose tissue of the Cas
HF group compared with the Cas or Soy HF groups. TIMP3 and MMP2 expressions were also higher in the adipose tissue of rats fed a Cas HF diet than in rats fed a Soy HF diet (Table 3). This means that angiogenesis and extracellular matrix remodelling are induced in obese rats due to augmented adiposity and the necessity to produce more vessels or branch pre-existing vessels.

Table 2. Serum leptin, insulin, glucose, TAG and cholesterol concentration in rats fed casein (Cas) or soya protein (Soy) containing adequate or highfat content for $160 \mathrm{~d}$

(Mean values with their standard errors, $n 15$ )

\begin{tabular}{|c|c|c|c|c|c|c|c|c|c|c|c|}
\hline \multirow[b]{2}{*}{ Parameter } & \multicolumn{2}{|c|}{ Cas } & \multicolumn{2}{|c|}{ Soy } & \multicolumn{2}{|c|}{ Cas HF } & \multicolumn{2}{|c|}{ Soy HF } & \multicolumn{3}{|c|}{$P$} \\
\hline & Mean & SE & Mean & SE & Mean & SE & Mean & SE & Protein & Fat & Protein $\times$ fat \\
\hline Leptin (mg/l) & $30 \cdot 8^{\mathrm{c}}$ & 0.7 & $21 \cdot 2^{d}$ & 2 & $80 \cdot 7^{a}$ & 2 & $41.4^{\mathrm{b}}$ & 4 & 0.0002 & $<0.0001$ & 0.005 \\
\hline Insulin (pg/ml) & $515^{\mathrm{b}}$ & $59 \cdot 8$ & $115^{\mathrm{c}}$ & $27 \cdot 2$ & $845^{\mathrm{a}}$ & 195 & $478^{b}$ & 55 & NS & NS & 0.05 \\
\hline Glucose $(\mathrm{mmol} / \mathrm{l})$ & $5 \cdot 05^{\mathrm{b}}$ & 0.07 & $5.00^{\mathrm{b}}$ & 0.29 & $6 \cdot 83^{a}$ & 0.06 & $6 \cdot 24^{\mathrm{a}, \mathrm{b}}$ & 0.15 & NS & $<0.001$ & NS \\
\hline TAG (mmol/l) & $0.42^{\mathrm{a}}$ & 0.09 & $0.24^{b}$ & 0.05 & $0.43^{\mathrm{a}}$ & 0.03 & $0.36^{a, b}$ & 0.05 & 0.026 & NS & NS \\
\hline Cholesterol (mmol/l) & $2 \cdot 29^{a, b}$ & 0.05 & $2 \cdot 08^{\mathrm{b}}$ & 0.05 & $2 \cdot 50^{\mathrm{a}}$ & 0.08 & $2 \cdot 57^{\mathrm{a}}$ & 0.06 & NS & NS & NS \\
\hline
\end{tabular}

Cas HF, Cas high-fat; Soy HF, Soy high-fat.

a,b,c,d Mean values with unlike superscript letters within a row were significantly different $(P<0.05)$. 
Table 3. Relative mRNA abundance of the renin-angiotensin system and angiogenesis-related genes in in rats fed casein (Cas) or soya protein (Soy) containing adequate or high-fat content for $160 \mathrm{~d}$

(Mean values with their standard errors, $n 5$ )

\begin{tabular}{|c|c|c|c|c|c|c|c|c|c|c|c|}
\hline \multirow[b]{2}{*}{ Gene } & \multicolumn{2}{|c|}{ Cas } & \multicolumn{2}{|c|}{ Soy } & \multicolumn{2}{|c|}{ Cas HF } & \multicolumn{2}{|c|}{ Soy HF } & \multicolumn{3}{|c|}{$P$} \\
\hline & Mean & SE & Mean & SE & Mean & SE & Mean & SE & Protein & Fat & Protein $\times$ fat \\
\hline \multicolumn{12}{|c|}{ Angiotensin-related genes } \\
\hline ACE & $1^{\mathrm{b}}$ & 0.4 & $0.58^{\mathrm{b}}$ & 0.3 & $3.59^{\mathrm{a}}$ & 0.5 & $3.49^{\mathrm{a}}$ & 0.4 & NS & $<0.0001$ & NS \\
\hline Agt & $1^{\mathrm{a}}$ & 0.3 & $0.83^{a, b}$ & 0.1 & $0.32^{\mathrm{c}}$ & 0.02 & $0.62^{b, c}$ & 0.1 & NS & 0.002 & 0.038 \\
\hline ATR1 & $1^{\mathrm{c}}$ & 0.3 & $0.31^{d}$ & 0.04 & $2 \cdot 51^{\mathrm{b}}$ & 0.3 & $3 \cdot 72^{\mathrm{a}}$ & 0.5 & NS & $<0.0001$ & 0.002 \\
\hline ATR2 & 1 & 0.5 & $2 \cdot 74$ & 1.4 & 0.79 & 0.4 & 0.9 & 0.3 & NS & NS & NS \\
\hline \multicolumn{12}{|c|}{ Angiogenesis-related genes } \\
\hline VEGFa & $1^{\mathrm{b}}$ & 0.05 & $0.95^{b}$ & 0.04 & $1 \cdot 14^{\mathrm{a}}$ & 0.07 & $0.94^{\mathrm{b}}$ & 0.07 & NS & NS & NS \\
\hline TIMP3 & $1^{\mathrm{b}}$ & 0.04 & $0.98^{b}$ & 0.06 & $1 \cdot 17^{\mathrm{a}}$ & 0.07 & $0.77^{\mathrm{c}}$ & 0.05 & NS & NS & 0.05 \\
\hline Angiopoietin 2 & $1^{\mathrm{b}}$ & 0.06 & $0.99^{b}$ & 0.04 & $1 \cdot 14^{a}$ & 0.08 & $1.04^{\mathrm{b}}$ & 0.08 & NS & NS & NS \\
\hline MMP2 & $1^{\mathrm{a}}$ & 0.05 & $0.95^{\mathrm{a}}$ & 0.06 & $0.93^{a}$ & 0.08 & $0.75^{\mathrm{b}}$ & 0.04 & NS & NS & NS \\
\hline
\end{tabular}

Cas HF, Cas high-fat; Soy HF, Soy high-fat.

a,b,c,d Mean values with unlike superscript letters within a row were significantly different $(P<0.05)$.

\section{Akt phosphorylation in vitro}

In order to know whether Soy consumption can ameliorate angiotensin-induced Akt inactivation, adipocytes cultured from different groups were incubated with insulin or pre-incubated with angiotensin II before stimulation with insulin. Akt phosphorylation was always increased by insulin compared with the cultured control adipocytes. Increased Akt phosphorylation by insulin was impaired by angiotensin II in all groups (Fig. 2(A), (B) and (D)) except the Cas HF group (Fig. 2(C)). The latter indicates that angiotensin II intensifies the effect of insulin on Akt activation during obesity. Thus, in the Cas HF group, angiotensin II maintains Akt activation by possibly increasing fatty acid esterification and consequent fat storage. The activation of Akt promotes fat storage via glucose uptake, preadipocyte differentiation or adipogenesis ${ }^{(25)}$. However, regarding dietary protein, the extent of Akt phosphorylation of the basal and insulin-stimulated states is higher in the adipocytes of rats fed Soy or Soy HF in contrast to the adipocytes in the Cas or Cas HF groups.

\section{Adipocyte size and in vitro angiotensin release}

Fat cell size resulted in larger retroperitoneal fat depot of rats fed Cas compared with rats fed Soy, and also in HF groups $v$. controls. This indicates that the consumption of a Cas diet

\begin{tabular}{|c|c|c|c|}
\hline Insulin & - & + & + \\
\hline Angiotensin II & - & - & + \\
\hline
\end{tabular}

\begin{tabular}{|l|l|l|}
\hline- & + & + \\
\hline- & - & + \\
\hline
\end{tabular}

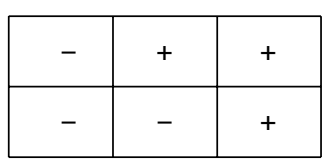

\begin{tabular}{|l|l|l|}
\hline- & + & + \\
\hline- & - & + \\
\hline
\end{tabular}

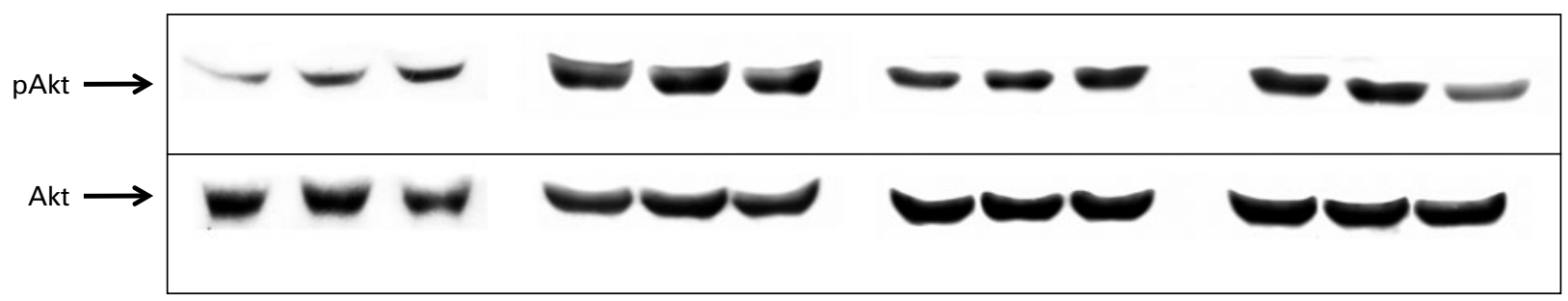

(A)

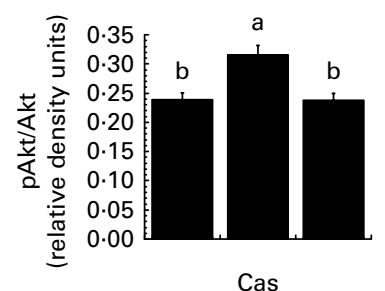

(B)

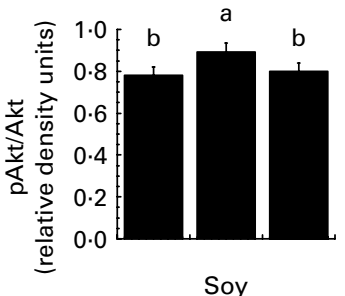

(C)

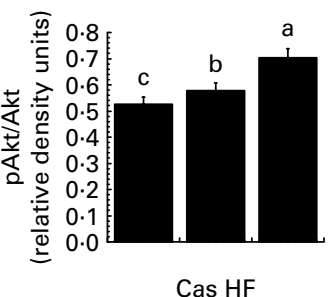

(D)

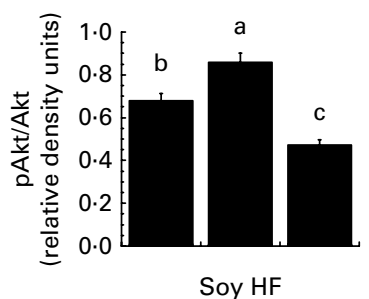

Fig. 2. Akt activation induced by insulin is altered by angiotensin II in adipocytes from rats fed soya protein (Soy). Adipocytes were prepared from rats fed the experimental diets for $160 \mathrm{~d}$ and were hormonally stimulated with insulin: $10^{-7} \mathrm{M}$ and angiotensin: $100 \mathrm{~nm}$. Cell homogenates were subjected to immunoblotting with the anti-Akt antibody. Arbitrary density units of phosphorylated Akt (pAkt)/total Akt are shown for (A) casein (Cas), (B) Soy, (C) Cas high-fat (Cas HF), (D) Soy high-fat (Soy HF) adipocytes not stimulated, stimulated with insulin or with insulin and angiotensin II. Values are means, with their standard errors represented by vertical bars, $n 5 .{ }^{\text {a,b,c }}$ Mean values with unlike letters were significantly different $(P<0.05)$. 

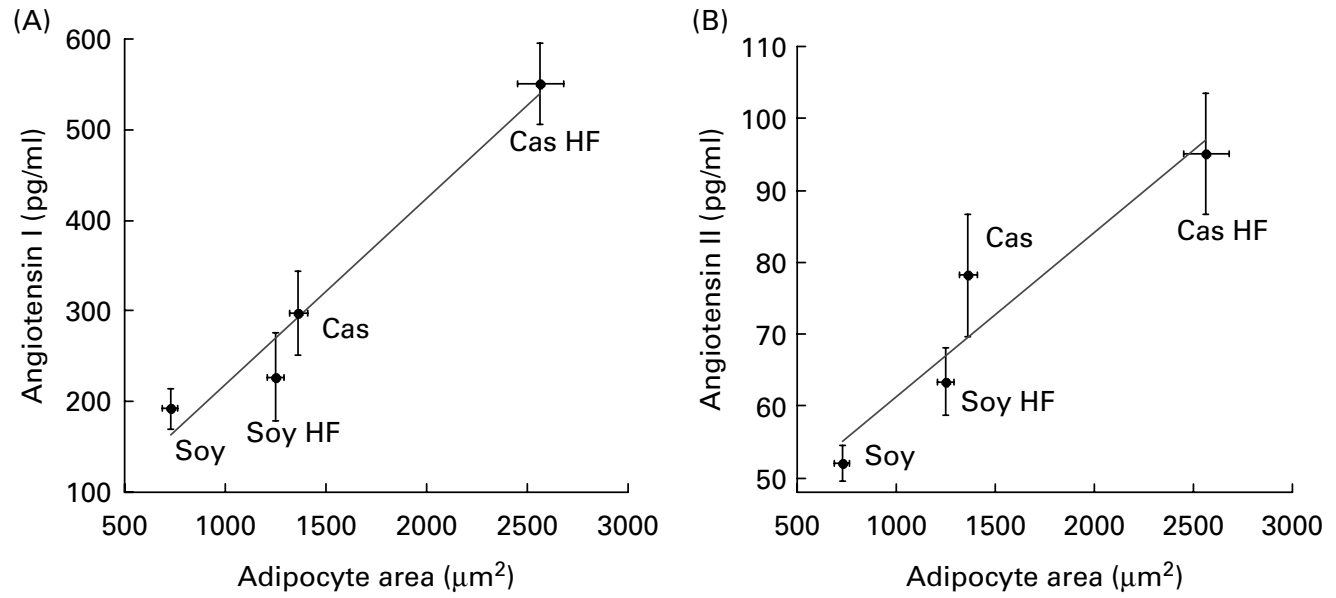

Fig. 3. Lower angiotensin release by adipocytes of rats fed soya protein (Soy) correlates with decreased adipocyte area. (A) Media concentration of angiotensin I $(R 0.98 ; P=0.018)$ and $(\mathrm{B})$ angiotensin II $(R 0.95 ; P=0.049)$ are directly associated with adipocyte size in a model of diet-induced obesity in rats fed casein (Cas), Cas high-fat (Cas HF), Soy and Soy high-fat (Soy HF) for $160 \mathrm{~d}$. Values are means, with their standard errors represented by vertical bars, $n 5$. Significant correlation is indicated $(P<0.05)$.

containing a high dietary fat concentration was associated with an increased adipocyte area (data not shown). Interestingly, adipocyte hypertrophy was directly associated with the concentration of angiotensin I (Fig. 3(A)) and II (Fig. 3(B)) that was released into the media from cultured fat cells with significant correlations $(R 0.98 ; P<0.018$, and 0.95; $P<0.049$, respectively). Thus, increased adipocyte volume, which has been associated with adipose tissue dysfunction, can predict an augmented local angiotensin I and angiotensin II release because the systemic concentration of both hormones did not change due to dietary treatments.

\section{Adipose tissue vascularisation}

Because angiotensin is a potent vasoconstrictor, its action may be related to the area of the blood vessels ${ }^{(26)}$. Furthermore, hypoxia or impaired angiogenesis is a feature of the decreased function of adipocytes ${ }^{(27)}$. Therefore, we calculated the number and area of blood vessels in the adipose tissue of rats fed with dietary treatments. The area containing vessels was $37 \%$ higher in the Soy group, which was in contrast with the Cas group (Fig. 4(A)). Also, the number of blood vessels was twofold higher in the adipose tissue of rats fed Soy HF than those fed Cas HF (Fig. 4(B)). These results indicate that Soy positively modifies adipose tissue vascularisation in different ways depending on the addition of dietary fat.

\section{Discussion}

Obesity, a disease that is characterised by increased adiposity, has become a world health problem. The presence of dysfunctional adipocytes in the adipose tissue in animal models of obesity and in obese humans has been related to the development of the metabolic syndrome ${ }^{(3)}$. Dietary strategies to avoid the mass growth of adipose tissue and impaired metabolism include modifications in carbohydrate and lipid type as well as content ${ }^{(28)}$. Nevertheless, few studies have addressed the influence of dietary protein on adipocyte function ${ }^{(20)}$.
The results of the present study show that dietary protein also modifies the RAS and angiogenesis components in the adipose tissue, as well as Akt phosphorylation associated with angiotensin II in the adipocytes of rats.

To induce obesity in the rat, it is necessary to increase fat content in the diet above $40 \%$ since the rat model is resistant to developing obesity with dietary treatments that include lower fat concentrations ${ }^{(29,30)}$. Indeed, commercial and homemade HF diets are formulated to contain $45 \%$ energy from fat in order to induce obesity and the metabolic syndrome. It was interesting to observe that rats fed the soya diet gained significantly less weight than those fed the Cas diet. This is in agreement with previous studies in our group that demonstrate that the consumption of the Soy diet promotes lower weight gain, and this is accompanied by a significantly lesser accumulation of retroperitoneal fat pads ${ }^{(20)}$. However, this difference was not observed during the first $60 \mathrm{~d}$ of the study, when the rats had a higher requirement of protein, suggesting that differences in final body weight are not due to differences in protein quality. Consequently, there was a decrease in the circulating leptin accompanied by lower serum insulin and TAG concentrations in comparison with the Cas HF group. The prevention of hyperinsulinaemia by Soy is indicative of the maintenance of insulin sensitivity ${ }^{(31)}$ in these rats despite the consumption of a HF diet. Thus, Soy may promote an appropriate activation of the insulin pathway ${ }^{(32,33)}$. In contrast, the hyperinsulinaemia observed in rats fed a Cas-HF diet was associated with a high TAG serum concentration, and this is in agreement with previous observations where hyperinsulinaemia in mice has been correlated with hypertriacylglycerolaemia and reduced insulin receptor binding ${ }^{(34)}$.

Soy intake was found to promote not only diminished circulating insulin concentration but also higher levels of basal and insulin-mediated Akt phosphorylation in adipocyte culture. Akt is activated in the adipose tissue to induce glucose uptake via Glut- 4 membrane translocation ${ }^{(35,36)}$. Additionally, Akt phosphorylation is necessary and sufficient to stimulate adipogenesis as demonstrated in Akt 1 knockout mice, 


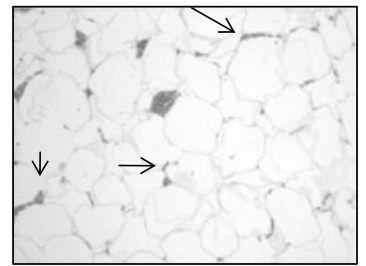

Cas
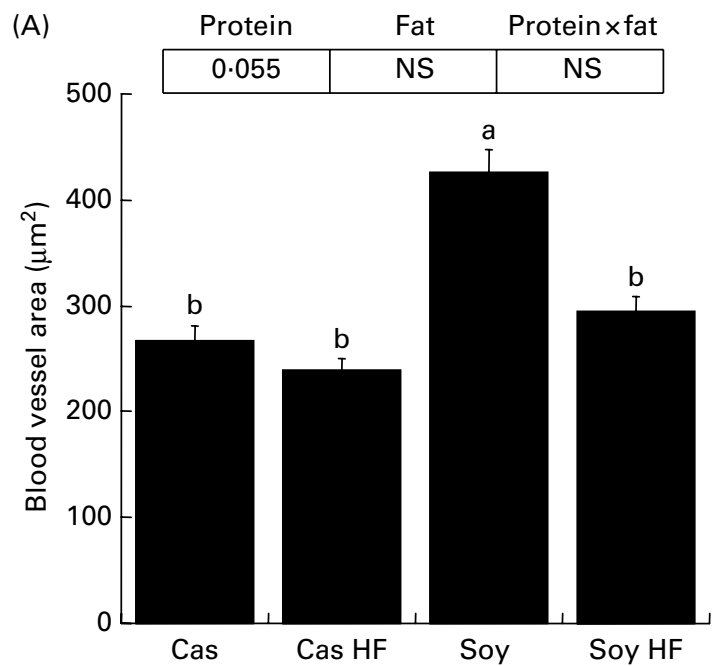

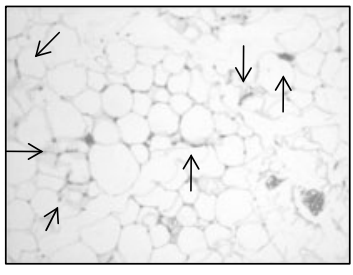

Soy

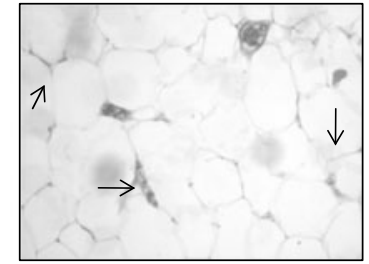

Soy HF

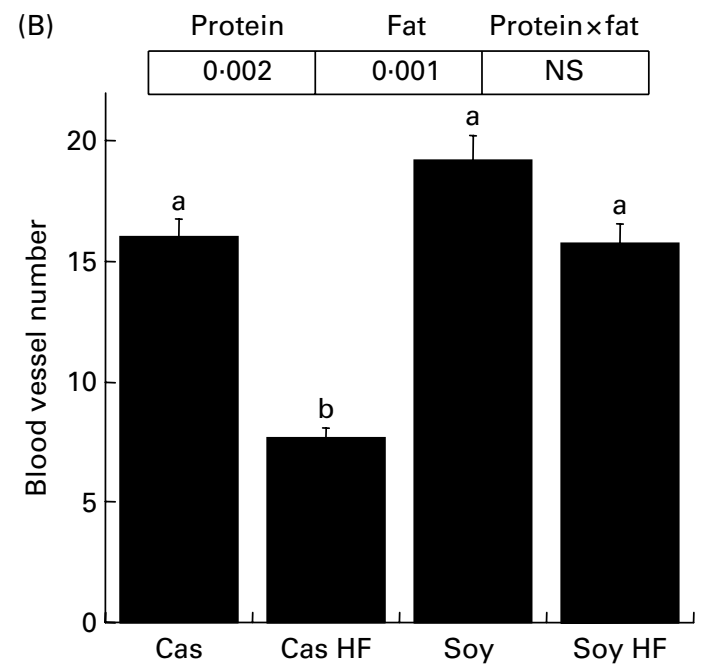

Fig. 4. Adipose tissue vascularisation is increased by dietary soya protein (Soy). (A) Blood vessel area and (B) blood vessel number in adipose tissue of rats fed casein (Cas), Cas high-fat (Cas HF), Soy and Soy high-fat (Soy HF) for $160 \mathrm{~d}$. Values are means, with their standard errors represented by vertical bars, $n$. ${ }^{\mathrm{a}, \mathrm{b}}$ Mean values with unlike letters were significantly different $(P<0.05)$.

which are unable to induce the differentiation programme by PPAR- $\gamma^{(37)}$. Furthermore, Akt has been described as a mediator of the insulin-like growth factor-1 receptor signal cascade for inducing adipogenesis ${ }^{(38)}$. In turn, adipogenesis regulates angiogenesis $^{(39,40)}$, and this process has also been related to Akt activation. VEGF and angiopoietins promote vascular homeostasis and angiogenesis through the activation of Akt signalling ${ }^{(41)}$. Akt also increases NO production and regulates vascular tone ${ }^{(42,43)}$. Subsequently, increased Akt activation in the isolated adipocytes of rats that were fed Soy suggests enhanced adipocyte differentiation and blood vessel formation. These results are in agreement with our findings regarding increased blood vessel area and number in the adipose tissue of the Soy groups. As we previously demonstrated, the TAG:DNA ratio was reduced in the adipose tissue of rats that consumed Soy ${ }^{(20)}$, thus confirming the presence of numerous smaller adipocytes in a more active adipogenic tissue.

Interestingly, the expression of VEGF, angiopoietin 2, MMP2 and TIMP3 mRNA was greater in the adipose tissue of rats fed a HF Cas diet in comparison with a HF Soy diet. Indeed, VEGF is the most critical factor initiating adipose angiogenesis in response to hypoxia. Blood vessel sprouting is accompanied by extracellular matrix degradation by MMPs and TIMP ${ }^{(44)}$. Subsequently, these angiogenic genes can be up-regulated in response to adipose tissue growth and adipocyte enlargement when alternative vascularisation is mandatory. Together, these results show that obesity in Cas HF rats induces angiogenesisassociated gene expression.

Angiogenesis in obesity conditions can be influenced by adipokine-mediated Akt activation. For instance, adiponectin stimulation of human macrophages promotes TIMP1 release through IL-10 induction ${ }^{(45)}$, new vessel growth through AMP-activated protein kinase and Akt in endothelial cells ${ }^{(46)}$. Also, leptin influences angiogenesis in the cornea and endothelial cell migration, proliferation and MMP and VEGF expression ${ }^{(47-49)}$. Thus, the hyperleptinaemia observed in the Cas HF group coincides with the augmented angiogenic gene expression. Angiotensin II is also an adipokine (not exclusively secreted by adipocytes) that has been implicated in the regulation of angiogenesis ${ }^{(50,51)}$ via ATR $1^{(52,53)}$ and the consequent augmented expression of VEGF. When we incubated adipocytes with angiotensin II, the hormone decreased insulin-stimulated Akt phosphorylation in all groups except in the obese group that was fed the Cas HF diet. Thus, it is possible that angiogenic genes can be up-regulated in the adipose tissue of obese animals due to angiotensin-mediated Akt activation. In the non-obese groups, angiotensin II reversed the effects of insulin phosphorylating Akt, probably because of adequate adipose vascularisation, regulated recruitment of new adipocytes, and decreased flux towards TAG accumulation. In contrast, adipocytes from obese rats locally released increased concentrations of angiotensin II, possibly to maintain vascularity and blood flow ${ }^{(54,55)}$ while the adipose tissue was being expanded. 
Angiotensin has been proposed as a molecular link between hypertension, insulin resistance and obesity because RAS components are extensively expressed during obesity. The expression of RAS components was also studied in this model. Increased ATR1 and ACE mRNA in the adipose tissue of rats that were fed HF diets is in agreement with the fructose-fed rat model $^{(56)}$ and human obesity ${ }^{(12)}$. In fact, ATR1a deficiency protects rodents from high-fat-induced obesity ${ }^{(57)}$. These results may imply that increased local angiotensin II release and high expression of ATR1 greatly stimulate ATR1 signalling in an autocrine fashion in adipocytes. Angiotensin II via ATR1 inhibits adipocyte differentiation and promotes adipocyte hypertrophy ${ }^{(58)}$. These metabolic adaptations agree with our results in the adipose tissue of obese rats where increased ATR1 mRNA, angiotensin release and adipocyte hypertrophy concur. Interestingly, Soy ameliorates the abnormalities promoted by angiotensin during obesity.

In summary, Soy consumption promotes increased basal and insulin-stimulated Akt activation, beneficially modifies the expression of RAS components and maintains the vascularity and cell size of adipocytes in a diet-induced obesity model. Therefore, the type of dietary protein can maintain adipocyte functionality.

\section{Acknowledgements}

The present study was supported by the National Council of Science and Technology, grant 46135-M. M. E. F. conducted the experimental research, analysed the data, and contributed to the manuscript. N. T. contributed to the analysis of the data and to the discussion of the manuscript. A. R. T. designed the study, analysed the data, and wrote the manuscript. The authors had no conflicts of interest.

\section{References}

1. Zhang Y, Proenca R, Maffei M, et al. (1994) Positional cloning of the mouse obese gene and its human homologue. Nature 372, 425-432.

2. Vazquez-Vela ME, Torres N \& Tovar AR (2008) White adipose tissue as endocrine organ and its role in obesity. Arch Med Res 39, 715-728.

3. Hajer GR, van Haeften TW \& Visseren FL (2008) Adipose tissue dysfunction in obesity, diabetes, and vascular diseases. Eur Heart J 29, 2959-2971.

4. Karastergiou K \& Mohamed-Ali V (2010) The autocrine and paracrine roles of adipokines. Mol Cell Endocrinol 318, 69-78.

5. Engeli S, Schling P, Gorzelniak K, et al. (2003) The adiposetissue renin-angiotensin-aldosterone system: role in the metabolic syndrome? Int J Biochem Cell Biol 35, 807-825.

6. Scheen AJ (2004) Renin-angiotensin system inhibition prevents type 2 diabetes mellitus. Part 1. A meta-analysis of randomised clinical trials. Diabetes Metab 30, 487-496.

7. Crandall DL, Herzlinger HE, Saunders BD, et al. (1994) Distribution of angiotensin II receptors in rat and human adipocytes. J Lipid Res 35, 1378-1385.

8. Endoh M (1998) Regulation of myocardial contractility by a downstream mechanism. Circ Res 83, 230-232.
9. Takanashi M \& Endoh M (1991) Characterization of positive inotropic effect of endothelin on mammalian ventricular myocardium. Am J Physiol 261, H611-H619.

10. Massiera F, Bloch-Faure M, Ceiler D, et al. (2001) Adipose angiotensinogen is involved in adipose tissue growth and blood pressure regulation. FASEB J 15, 2727-2729.

11. Pausova Z (2006) From big fat cells to high blood pressure: a pathway to obesity-associated hypertension. Curr Opin Nephrol Hypertens 15, 173-178.

12. Van Harmelen V, Ariapart P, Hoffstedt J, et al. (2000) Increased adipose angiotensinogen gene expression in human obesity. Obes Res $\mathbf{8}, 337-341$.

13. Gorzelniak K, Engeli S, Janke J, et al. (2002) Hormonal regulation of the human adipose-tissue renin-angiotensin system: relationship to obesity and hypertension. J Hypertens 20, 965-973.

14. Boschmann M, Ringel J, Klaus S, et al. (2001) Metabolic and hemodynamic response of adipose tissue to angiotensin II. Obes Res 9, 486-491.

15. Folli F, Kahn CR, Hansen H, et al. (1997) Angiotensin II inhibits insulin signaling in aortic smooth muscle cells at multiple levels. A potential role for serine phosphorylation in insulin/angiotensin II crosstalk. J Clin Invest 100, 2158-2169.

16. Baudry A, Yang ZZ \& Hemmings BA (2006) PKBalpha is required for adipose differentiation of mouse embryonic fibroblasts. J Cell Sci 119, 889-897.

17. Peng XD, Xu PZ, Chen ML, et al. (2003) Dwarfism, impaired skin development, skeletal muscle atrophy, delayed bone development, and impeded adipogenesis in mice lacking Akt1 and Akt2. Genes Dev 17, 1352-1365.

18. Yun SJ, Kim EK, Tucker DF, et al. (2008) Isoform-specific regulation of adipocyte differentiation by Akt/protein kinase Balpha. Biochem Biophys Res Commun 371, 138-143.

19. Gerber HP, McMurtrey A, Kowalski J, et al. (1998) Vascular endothelial growth factor regulates endothelial cell survival through the phosphatidylinositol 3(-kinase/Akt signal transduction pathway. Requirement for Flk-1/KDR activation. J Biol Chem 273, 30336-30343.

20. Frigolet ME, Torres N, Uribe-Figueroa L, et al. (2011) White adipose tissue genome wide-expression profiling and adipocyte metabolic functions after soy protein consumption in rats. J Nutr Biochem 22, 118-129.

21. Chomczynski P \& Sacchi N (1987) Single-step method of RNA isolation by acid guanidinium thiocyanate-phenolchloroform extraction. Anal Biochem 162, 156-159.

22. Rodbell M (1967) Metabolism of isolated fat cells. VI. The effects of insulin, lipolytic hormones, and theophylline on glucose transport and metabolism in "ghosts". J Biol Chem 242, 5751-5756.

23. Lowry OH, Rosebrough NJ, Farr AL, et al. (1951) Protein measurement with the Folin phenol reagent. I Biol Chem 193, 265-275.

24. Torre-Villalvazo I, Tovar AR, Ramos-Barragan VE, et al. (2008) Soy protein ameliorates metabolic abnormalities in liver and adipose tissue of rats fed a high fat diet. $J$ Nutr 138, 462-468.

25. Fayard E, Xue G, Parcellier A, et al. (2010) Protein kinase B (PKB/Akt), a key mediator of the PI3K signaling pathway. Curr Top Microbiol Immunol 346, 31-56.

26. Assali NS \& Westersten A (1961) Regional flow-pressure relationship in response to angiotensin in the intact dog and sheep. Circ Res 9, 189-193. 
27. Wood IS, de Heredia FP, Wang B, et al. (2009) Cellular hypoxia and adipose tissue dysfunction in obesity. Proc Nutr Soc 68, 370-377.

28. Abete I, Astrup A, Martinez JA, et al. (2010) Obesity and the metabolic syndrome: role of different dietary macronutrient distribution patterns and specific nutritional components on weight loss and maintenance. Nutr Rev 68, 214-231

29. Buettner R, Scholmerich J \& Bollheimer LC (2007) High-fat diets: modeling the metabolic disorders of human obesity in rodents. Obesity (Silver Spring) 15, 798-808.

30. Ghibaudi L, Cook J, Farley C, et al. (2002) Fat intake affects adiposity, comorbidity factors, and energy metabolism of Sprague-Dawley rats. Obes Res 10, 956-963.

31. Noriega-Lopez L, Tovar AR, Gonzalez-Granillo $\mathrm{M}$, et al. (2007) Pancreatic insulin secretion in rats fed a soy protein high fat diet depends on the interaction between the amino acid pattern and isoflavones. $J$ Biol Chem 282, 20657-20666.

32. Paz K, Hemi R, LeRoith D, et al. (1997) A molecular basis for insulin resistance. Elevated serine/threonine phosphorylation of IRS-1 and IRS-2 inhibits their binding to the juxtamembrane region of the insulin receptor and impairs their ability to undergo insulin-induced tyrosine phosphorylation. I Biol Chem 272, 29911-29918.

33. Zick Y (2001) Insulin resistance: a phosphorylation-based uncoupling of insulin signaling. Trends Cell Biol $\mathbf{1 1}$ 437-441.

34. Shanik MH, Xu Y, Skrha J, et al. (2008) Insulin resistance and hyperinsulinemia: is hyperinsulinemia the cart or the horse? Diabetes Care 31 (Suppl. 2), S262-S268.

35. Cong LN, Chen H, Li Y, et al. (1997) Physiological role of Akt in insulin-stimulated translocation of GLUT4 in transfected rat adipose cells. Mol Endocrinol 11, 1881-1890.

36. Yancopoulos GD, Davis S, Gale NW, et al. (2000) Vascularspecific growth factors and blood vessel formation. Nature 407, 242-248

37. Zhang HH, Huang J, Duvel K, et al. (2009) Insulin stimulates adipogenesis through the Akt-TSC2-mTORC1 pathway. PLOS One 4, e6189.

38. Xu J \& Liao K (2004) Protein kinase B/AKT 1 plays a pivotal role in insulin-like growth factor-1 receptor signaling induced 3T3-L1 adipocyte differentiation. J Biol Chem 279, 35914-35922.

39. Crandall DL, Busler DE, McHendry-Rinde B, et al. (2000) Autocrine regulation of human preadipocyte migration by plasminogen activator inhibitor-1. J Clin Endocrinol Metab 85, 2609-2614.

40. Hausman GJ (1982) Adipocyte development in subcutaneous tissues of the young rat. Acta Anat (Basel) $\mathbf{1 1 2}$ $185-196$

41. Shiojima I \& Walsh K (2002) Role of Akt signaling in vascular homeostasis and angiogenesis. Circ Res 90, 1243-1250.

42. Dimmeler S, Fleming I, Fisslthaler B, et al. (1999) Activation of nitric oxide synthase in endothelial cells by Akt-dependent phosphorylation. Nature 399, 601-605.
43. Fulton D, Gratton JP, McCabe TJ, et al. (1999) Regulation of endothelium-derived nitric oxide production by the protein kinase Akt. Nature 399, 597-601.

44. Pepper MS (2001) Role of the matrix metalloproteinase and plasminogen activator-plasmin systems in angiogenesis. Arterioscler Thromb Vasc Biol 21, 1104-1117.

45. Kumada M, Kihara S, Ouchi N, et al. (2004) Adiponectin specifically increased tissue inhibitor of metalloproteinase- 1 through interleukin-10 expression in human macrophages. Circulation 109, 2046-2049.

46. Ouchi N, Kobayashi H, Kihara S, et al. (2004) Adiponectin stimulates angiogenesis by promoting cross-talk between AMP-activated protein kinase and Akt signaling in endothelial cells. J Biol Chem 279, 1304-1309.

47. Bouloumie A, Drexler HC, Lafontan M, et al. (1998) Leptin, the product of $\mathrm{Ob}$ gene, promotes angiogenesis. Circ Res 83, 1059-1066.

48. Park HY, Kwon HM, Lim HJ, et al. (2001) Potential role of leptin in angiogenesis: leptin induces endothelial cell proliferation and expression of matrix metalloproteinases in vivo and in vitro. Exp Mol Med 33, 95-102.

49. Sierra-Honigmann MR, Nath AK, Murakami C, et al. (1998) Biological action of leptin as an angiogenic factor. Science 281, 1683-1686.

50. Fernandez LA, Tarlatzis BC, Rzasa PJ, et al. (1985) Renin-like activity in ovarian follicular fluid. Fertil Steril 44, 219-223.

51. Le Noble FA, Hekking JW, Van Straaten HW, et al. (1991) Angiotensin II stimulates angiogenesis in the chorio-allantoic membrane of the chick embryo. Eur J Pharmacol 195, 305-306.

52. Sasaki K, Murohara T, Ikeda H, et al. (2002) Evidence for the importance of angiotensin II type 1 receptor in ischemiainduced angiogenesis. J Clin Invest 109, 603-611.

53. Shimizu T, Okamoto H, Chiba S, et al. (2003) VEGFmediated angiogenesis is impaired by angiotensin type 1 receptor blockade in cardiomyopathic hamster hearts. Cardiovasc Res 58, 203-212.

54. Goossens GH, Blaak EE, Saris WH, et al. (2004) Angiotensin II-induced effects on adipose and skeletal muscle tissue blood flow and lipolysis in normal-weight and obese subjects. J Clin Endocrinol Metab 89, 2690-2696.

55. Goossens GH, McQuaid SE, Dennis AL, et al. (2006) Angiotensin II: a major regulator of subcutaneous adipose tissue blood flow in humans. J Physiol 571, 451-460.

56. Giacchetti G, Sechi LA, Griffin CA, et al. (2000) The tissue renin-angiotensin system in rats with fructose-induced hypertension: overexpression of type 1 angiotensin II receptor in adipose tissue. J Hypertens 18, 695-702.

57. Kouyama R, Suganami T, Nishida J, et al. (2005) Attenuation of diet-induced weight gain and adiposity through increased energy expenditure in mice lacking angiotensin II type 1a receptor. Endocrinology 146, 3481-3489.

58. Sharma AM, Janke J, Gorzelniak K, et al. (2002) Angiotensin blockade prevents type 2 diabetes by formation of fat cells. Hypertension 40, 609-611. 